\title{
Preparation of Barium Titanyl Oxalate Tetrahydrate for Conversion to Barium Titanate of High Purity
}

\author{
W. Stanley Clabaugh, Edward M. Swiggard, and Raleigh Gilchrist
}

\begin{abstract}
A procedure is described for preparing barium titanyl oxalate tetrahydrate, $\mathrm{BaTiO}\left(\mathrm{C}_{2} \mathrm{O}_{4}\right)_{2} \cdot 4 \mathrm{H}_{2} \mathrm{O}$, in which the mole ratio of $\mathrm{TiO}_{2}$ to $\mathrm{BaO}$ is unity. To achieve this ratio the salt must be precipitated from solutions that do not contain sodium, potassium, or ammonium ions.

Ignition of barium titanyl oxalate tetrahydrate produces barium titanate, $\mathrm{BaTiO}_{3}$. To prepare barium titanate free of strontium, the barium chloride used must be specially purified.
\end{abstract}

\section{Introduction}

Titanium forms an extensive series of compounds called titanates in which the titanium plays the role of an acidic constituent. Of particular interest have been barium titanate, $\mathrm{BaTiO}_{3}$, and various titanates in which the barium has been partially replaced by strontium, magnesium, calcium, etc., and the titanium by zirconium or other acidic metals.

Owing to the possession of desirable dielectric and piezoelectric properties, these titanates, in recent years, have come into very extensive use in various electronic devices. In spite of their wide use the relationship between composition and electrical characteristics has not yet been fully worked out, in part because of the presence of minor components originating as impurities in the titanium dioxide and the barium carbonate used as starting materials in commercial production. The usual method of preparing barium titanate dielectrics is to calcine at specified temperatures mechanically-ground, intimate mixtures of titanium dioxide and barium carbonate.

The ultimate object of the work here described was to prepare barium titanate in which the mole ratio of barium to titanium was exactly unity and in which the impurities were reduced to an insignificant amount. This would enable the ceramic engineer to determine systematically the effect of various substituting elements on the electrical properties and to arrive at a composition that would reproducibly give the most desirable product.

\section{Preparation of Barium Titanyl Oxalate, $\mathrm{BaTiO}\left(\mathrm{C}_{2} \mathrm{O}_{4}\right)_{2} \cdot 4 \mathrm{H}_{2} \mathrm{O}$}

Double oxalates of barium and titanium of the composition $\mathrm{BaC}_{2} \mathrm{O}_{4} \cdot \mathrm{TiO}\left(\mathrm{C}_{2} \mathrm{O}_{4}\right) \cdot x \mathrm{H}_{2} \mathrm{O}$ would be expected to yield on ignition a barium titanate in which the ratio of barium to titanium is exactly unity.

It has been known for some time that barium and titanium form an oxalate, described as a dihydrate, $\mathrm{BaTiO}\left(\mathrm{C}_{2} \mathrm{O}_{4}\right)_{2} \cdot 2 \mathrm{H}_{2} \mathrm{O}$. This compound is said to be formed by the reaction of $\mathrm{K}_{2} \mathrm{TiO}\left(\mathrm{C}_{2} \mathrm{O}_{4}\right)_{2}$ with barium

1 Financial support of this work was furnished by the Diamond Ordnance Fuze Laboratories. chloride [1]. ${ }^{2}$ Attempts to prepare this compound were not successful because potassium was not completely replaced by barium. The product always contained less barium than the stoichiometric amount. However, it was found possible to get the desired composition by slowly adding an aqueous solution of titanium tetrachloride and barium chloride, in which the two compounds are in nearly equimolar proportion but with barium in slight excess, to a hot solution of oxalic acid containing about 10 percent more of the acid than required for the desired double oxalate. The slight excess of barium and the somewhat greater excess of oxalate were intended to minimize competing reactions that might result in the formation of insoluble partially hydrolyzed compounds of titanium. The salt prepared in this way had the composition $\mathrm{BaTiO}\left(\mathrm{C}_{2} \mathrm{O}_{4}\right)_{2} \cdot 4 \mathrm{H}_{2} \mathrm{O}$. The detailed procedure used in preparing it in batches of $240 \mathrm{~g}$ was as follows.

\section{[2.1." Procedure}

Add $100 \mathrm{ml}$ of highly purified titanium tetrachloride [2], drop by drop, to 100 to $150 \mathrm{ml}$ of distilled water which is cooled in an ice bath. If the titanium tetrachloride is added slowly to the rapidly stirred distilled water, the resulting solution will be perfectly clear and free of hydrolyzed titanium. Dilute this solution to $500 \mathrm{ml}$ and determine its titanium content. The exact titanium content must be known because the quantities of barium chloride and of oxalic acid to be used are based on this value. Dissolve $165 \mathrm{~g}$ (0.675 mole) of barium chloride dihydrate in 1,600 $\mathrm{ml}$ of distilled water and cool the solution to room temperature. To this solution add the volume of titanium tetrachloride solution that contains exactly $32 \mathrm{~g}$ (0.668 mole) of titanium. The barium chloride solution must be stirred constantly during the mixing and the temperature maintained at or below $30^{\circ} \mathrm{C}$ to prevent hydrolysis of the titanium.

Dissolve $185 \mathrm{~g}$ (1.47 moles) of oxalic acid dihydrate in 1,000 $\mathrm{ml}$ of distilled water in a 4-liter beaker, and heat the resulting solution on the steam bath to $80^{\circ} \mathrm{C}$. It should be noted that the quantity of barium is 1 percent in excess and the quantity of

2 Figures in brackets indicate the literature references at the end of this paper. 
oxalate is 10 percent in excess of the stoichiometric amounts required to produce $\mathrm{BaTiO}\left(\mathrm{C}_{2} \mathrm{O}_{4}\right)_{2} \cdot 4 \mathrm{H}_{2} \mathrm{O}$. This oxalate solution must be stirred constantly during the addition of the solution containing barium and titanium chloride. The use of a mechanical stirrer is recommended. Add the barium-titanium solution slowly. A convenient way to do this is by means of a separatory funnel mounted above the beaker. The rate of addition is readily adjusted by means of the stopcock on the funnel.

When the solution of barium-titanium chlorides first mixes with the solution of oxalic acid, a white flocculent precipitate forms which redissolves on stirring. The slow addition of the barium-titanium solution is continued until a dense crystalline form of barium titanyl oxalate tetrahydrate begins to precipitate. At this point the rate of addition may be increased slightly. However, the rate should not be increased to the point where the flocculent precipitate that first forms will not redissolve and form the desired dense precipitate. From 2 to 3 hours are required for the addition of the 2 liters of bariumtitanium solution. At the end of the operation of mixing the 4-liter beaker is removed from the steam bath and the clear supernatant liquid decanted through a filter paper on a Büchner funnel. The precipitate is then washed by decantation with distilled water 5 or 6 times, transferred to the Büchner funnel, and again washed 5 or 6 times with distilled water. This precipitate will dry in the air and produce a fine, dry granular salt free of lumps or cakes. The drying may be hastened by drawing clean air through the salt for 3 to 4 hours.

The foregoing method was used many times in the preparation of batches of barium titanyl oxalate tetrahydrate which later were ignited to barium titanate. The mole ratio of $\mathrm{TiO}_{2}$ to $\mathrm{BaO}$, calculated from the results of the chemical analysis of the barium titanate resulting from the ignition of various batches of barium titanyl oxalate tetrahydrate, is given in table 1.

TABLE 1. Mole ratio of $\mathrm{Ti}$ to $\mathrm{Ba}$ as calculated from the determinations of $\mathrm{TiO}_{2}$ and $\mathrm{BaSO}_{4}$ on $0.5000-g$ samples of $\mathrm{BaTiO}_{3}$ formed by the ignition of various preparations of $\mathrm{BaTiO}\left(\mathrm{C}_{2} \mathrm{O}_{4}\right)_{2} \cdot 4 \mathrm{H}_{2} \mathrm{O}$ a

\begin{tabular}{|c|c|c|c|c|c|c|}
\hline Batch & Sample & $\mathrm{BaSc}$ & ${ }_{4}$ found & $\mathrm{TiO}$ & found & $\begin{array}{l}\text { Ratio of } \\
\text { Tito } \mathrm{Ba}\end{array}$ \\
\hline $\begin{array}{l}\mathrm{I} \\
\text { II } \\
\text { III } \\
\text { IV } \\
\mathrm{V} \\
\mathrm{VI} \\
\mathrm{VII} \\
\mathrm{VIII} \\
\mathrm{IX} \\
\mathrm{X} \\
\mathrm{XI} \\
\mathrm{X} I \mathrm{II} \\
\end{array}$ & $\left\{\begin{array}{r}1 \\
2 \\
3 \\
4 \mathrm{~A} \\
4 \mathrm{~B} \\
5 \mathrm{~A} \\
5 \mathrm{~B} \\
6 \mathrm{~A} \\
6 \mathrm{~B} \\
7 \mathrm{~A} \\
7 \mathrm{~B} \\
8 \\
9 \\
10 \\
11 \\
12\end{array}\right.$ & $\begin{array}{l}g \\
0.4995 \\
.4998 \\
.5010 \\
.5001 \\
.5001 \\
.5004 \\
.5004 \\
.5004 \\
.5005 \\
.5003 \\
.5004 \\
.5008 \\
.5010 \\
.5003 \\
.5008 \\
.5009\end{array}$ & \begin{tabular}{|l}
\multicolumn{1}{c}{ Mole } \\
2. $140 \times 10^{3}$ \\
2.141 \\
2.146 \\
2.142 \\
2.142 \\
2.144 \\
2.144 \\
2.144 \\
2.144 \\
2.143 \\
2.144 \\
2.145 \\
2.146 \\
2.143 \\
2.145 \\
2.146
\end{tabular} & $\begin{array}{l}g \\
0.1712 \\
.1712 \\
.1713 \\
.1715 \\
.1715 \\
.1712 \\
.1713 \\
.1713 \\
.1713 \\
.1712 \\
.1712 \\
.1712 \\
.1714 \\
.1713 \\
.1712 \\
.1712\end{array}$ & \begin{tabular}{|l|}
\multicolumn{1}{|c}{ Mole } \\
$2.143 \times 10^{3}$ \\
2.143 \\
2.144 \\
2.146 \\
2.146 \\
2.143 \\
2.144 \\
2.144 \\
2.144 \\
2.143 \\
2.143 \\
2.143 \\
2.145 \\
2.144 \\
2.143 \\
2.143
\end{tabular} & $\begin{array}{l}1.001 \\
1.001 \\
0.992 \\
1.002 \\
1.002 \\
1.000 \\
1.000 \\
1.000 \\
1.000 \\
1.000 \\
1.000 \\
0.999 \\
1.000 \\
1.001 \\
0.999 \\
.999\end{array}$ \\
\hline
\end{tabular}

a The 12 batches of $\mathrm{BaTiO}\left(\mathrm{C}_{2} \mathrm{O}_{4}\right)_{2} \cdot 4 \mathrm{H}_{2} \mathrm{O}$ were finally placed in a single container and mixed by tumbling. A sample was removed and ignited to $\mathrm{BaTiO}_{3}$. tainer and mixed by tumbling. A sample was removed and ignited to $\mathrm{BaTiO}_{3}$. The oxalate compound was again tumbled and sampled. This operation was
repeated a third time. Analysis of the three samples of $\mathrm{BaTiO}_{3}$ gave the follow. repeated a third time. Analysis of the three samples of $\mathrm{B}$.
ing results for the ratio of $\mathrm{Ti}$ to $\mathrm{Ba}: 1.000,1.001$, and 1.000 .

\section{Determination of Barium and Titanium in Barium Titanate}

To determine barium and titanium, samples of the various batches of barium titanyl oxalate tetrahydrate were first ignited to barium titanate. Conversion was done by heating the oxalate salt in a furnace at $900^{\circ} \mathrm{C}$, for convenience, overnight. A shorter period of ignition would probably have sufficed, but it was more convenient to heat overnight.

\subsection{Analytical Procedure}

Digest a $0.5-\mathrm{g}$ sample of barium titanate with 15 $\mathrm{ml}$ of concentrated hydrochloric acid by heating it gently with a burner until the yellow color of the solution disappears. Add $15 \mathrm{ml}$ of water and boil the solution gently until the sample dissolves completely.

It was observed that if the amount of basic constituent, on a mole basis, was equal to or greater than the amount of acid constituent the above procedure would effect complete solution of the sample. ${ }^{3}$

Dilute the solution containing the barium and titanium with $100 \mathrm{ml}$ of water and add $50 \mathrm{ml}$ of a solution of ethylenediamine tetraacetic acid made by dissolving $1.5 \mathrm{~g}$ of the reagent in $50 \mathrm{ml}$ of water with enough ammonium hydroxide to effect solution. Next, adjust the acidity of the barium-titanium solution to $p \mathrm{H} 3.5$ to 4.0 with diluted ammonium hydroxide. Heat the resulting solution to boiling: and precipitate the barium as barium sulfate by adding $20 \mathrm{ml}$ of a 25 -percent aqueous solution of ammonium sulfate. This large excess of ammonium sulfate is necessary to precipitate the barium completely at $p \mathrm{H} 3.5$ to 4.0 in the presence of the complexing agent. Digest the solution on the stream bath until the barium sulfate settles and the supernatant liquid becomes clear. Remove the precipitate by filtration, wash it with water, ignite it, weigh it as $\mathrm{BaSO}_{4}$, and calculate its $\mathrm{BaO}$ content.

Acidify the combined filtrate and washings with $20 \mathrm{ml}$ of concentrated sulfuric acid, cool the resulting solution to $10^{\circ} \mathrm{C}$, and precipitate the titanium with cupferron. Ignite the precipitate and weigh it as $\mathrm{TiO}_{2}$.

The use of ethylenediamine tetraacetic acid in the analytical separation of barium from titanium is essential because in its absence barium sulfate, even when precipitated from strongly acid solution, was found by qualitative spectrochemical examination to be contaminated by titanium. When the separation was made in the presence of the sequestering reagent, the qualitative spectrochemical examination indicated that the contamination was only 0.01 to 0.1 percent. The value of the mole ratio of $\mathrm{Ti}$ to $\mathrm{Ba}$, when determined on the same batch of barium

3 If, on the other hand, the acidic constituent was in excess, an insoluble residue would remain. Experience in analyzing the oxalate compound showed that when the titanium content significantly exceeded the unit ratio the resulting barium titanite did not dissolve completely. This behavior on solution furnished a rapid means of indicating excess titanium. 
titanate, was 0.991 in the absence of ethylenediamine tetraacetic acid and 1.000 in the presence of the reagent.

\section{Effect of Alkali Elements on the Com- position of Barium Titanyl Oxalate}

Titanium forms complexes with organic compounds such as oxalates, citrates, tartrates, etc., and this behavior is made use of to advantage in analyzing materials containing titanium. Ions such as potassium, sodium, ammonium, barium, etc., increase the stability of these titanium complexes. For example, if aqueous solutions of titanium tetrachloride and oxalic acid are mixed and boiled, the titanium will precipitate, even though a large excess of oxalic acid is present. The precipitated titanium will not redissolve in excess of either organic or mineral acid. If the acidity of the solution is made about $p \mathrm{H} 5$ to 6 by adding sodium, potassium, or ammonium hydroxide, and the solution then heated, the titanium precipitate will redissolve. Once a solution of titanium is obtained by digesting with an alkali oxalate at $p \mathrm{H} 5$ to 6 , this solution can be boiled without the titanium precipitating, even if the acidity is increased to a value more acid than $p H 1$.

Attempts were made to prepare barium titanyl oxalate by adding solutions of barium chloride to hot solutions of alkali titanium oxalate, as well as by adding solutions of the alkali titanium oxalate to hot solutions of barium chloride. In each instance the amounts taken were such that the mole ratios were 1 barium to 1 titanium to 2 oxalate. The barium titanyl oxalates so prepared were then analyzed. The oxalate was determined by titrating with $0.1 \mathrm{~N}$ potassium permanganate in a perchloric acid solution. The barium and the titanium were determined as described in section 3 . If the difference is assumed to be water, the compound had the formula $\mathrm{BaTiO}\left(\mathrm{C}_{2} \mathrm{O}_{4}\right)_{2} \cdot 4 \mathrm{H}_{2} \mathrm{O}$. Results of the analysis of the salts prepared by means of the sodium, the potassium, and the ammonium titanium oxalates are given in table 2 .

TABLE 2. Composition of barium titanyl oxalate tetrahydrate prepared by means of sodium, potassium, and ammonium oxalates

\begin{tabular}{|c|c|c|c|c|c|}
\hline \multirow{2}{*}{ Batch } & \multirow{2}{*}{$\begin{array}{l}\text { Ba per } \\
\text { gram of } \\
\text { salt }\end{array}$} & \multirow{2}{*}{$\begin{array}{l}\text { TiO per } \\
\text { gram of } \\
\text { salt }\end{array}$} & \multirow{2}{*}{$\begin{array}{c}\mathrm{C}_{2} \mathrm{O}_{4} \text { per } \\
\text { gram of } \\
\text { salt }\end{array}$} & \multicolumn{2}{|c|}{ Molar ratio } \\
\hline & & & & $\mathrm{C}_{2} \mathrm{O}_{4} / \mathrm{TiO}$ & $\mathrm{TiO} / \mathrm{Ba}$ \\
\hline $\begin{array}{l}\mathrm{I}^{\mathrm{a}_{2}} \\
\mathrm{II} \mathrm{b}_{\ldots} \\
\mathrm{III}^{\mathrm{o}}\end{array}$ & $\begin{array}{c}\text { Mole } \\
\left\{\begin{array}{l}2.107 \times 10^{3} \\
2.089\end{array}\right. \\
\left\{\begin{array}{l}2.055 \\
2.095\end{array}\right. \\
\left\{\begin{array}{l}2.113 \\
2.158 \\
2.210\end{array}\right.\end{array}$ & $\begin{array}{l}\quad \text { Mole } \\
\text { 2. } 261 \times 10^{3} \\
2.278 \\
2.313 \\
2.273 \\
2.226 \\
2.231 \\
2.223\end{array}$ & \begin{tabular}{l}
\multicolumn{1}{c}{ Mole } \\
4. $534 \times 10^{3}$ \\
4. 566 \\
4. 632 \\
4. 549 \\
4. 462 \\
4. 471 \\
4. 449
\end{tabular} & $\begin{array}{l}2.005 \\
2.004 \\
2.003 \\
2.001 \\
2.004 \\
2.004 \\
2.001\end{array}$ & $\begin{array}{l}\text { 1. } 073 \\
\text { 1. } 090 \\
1.126 \\
\text { 1. } 085 \\
\text { 1. } 053 \\
\text { 1. } 034 \\
\text { 1. } 006\end{array}$ \\
\hline
\end{tabular}

a Prepared from the sodium titanium oxalate.

b Prepared from the potassium titanium oxalate.

c Prepared from the ammonium titanium oxalate.
The results show that in each salt the mole ratio of titanium to oxalate was 1 to 2 , within the limits of experimental determination. However, in each salt the mole ratio of barium to titanium was not 1 to 1 , but the titanium was always in excess. Samples of each preparation were ignited at $900^{\circ} \mathrm{C}$. The ignition products of the salts formed from the potassium salt dissolved completely when treated with hydrochloric acid, as previously described, and the solutions were found to contain potassium. A similar situation existed in the case of the sodium product. The ignited products of the salts formed from the ammonium salts did not dissolve completely, but left a white insoluble residue, which was undissolved titanium oxide.

The explanation of these observations is that some of the barium in the $\mathrm{BaTiO}\left(\mathrm{C}_{2} \mathrm{O}_{4}\right)_{2} \cdot 4 \mathrm{H}_{2} \mathrm{O}$ is replaced by the alkali element. In the cases of sodium and potassium these elements are not lost on ignition but form $\mathrm{Na}_{2} \mathrm{TiO}_{3}$ and $\mathrm{K}_{2} \mathrm{TiO}_{3}$, which are soluble in solutions of hydrochloric acid. This is not the situation with the ammonium compound. In this case it is $\mathrm{TiO}_{2}$ and not $\left(\mathrm{NH}_{4}\right)_{2} \mathrm{TiO}_{3}$ that is formed on ignition. This ignited $\mathrm{TiO}_{2}$ is not soluble in hydrochloric acid. The observation was made that if the number of moles of basic constituents in the ignited titanates is equal to or greater than that of the acid constituents, the titanates will be soluble in solutions of hydrochloric acid.

\section{Preparation of Barium Titanate of High Purity}

In preparing barium titanate of high purity, highly refined titanium tetrachloride, specially purified strontium-free barium chloride, and specially purified oxalic acid were used. To ascertain whether reagent grade barium chloride and reagent grade oxalic acid, complying with the specifications of the American Chemical Society, would be suitable, barium titanate was likewise prepared from these reagents. The only difference between the products, when tested spectrochemically, was that the one prepared with reagent chemicals was found to contain a small amount of strontium estimated qualitatively to be between 0.01 and 0.1 percent.

If one desires a product free of strontium, the barium salt used must be specially purified to remove strontium before making the barium titanyl oxalate.

\section{References}

[1] Gmelins Handbuch der Anorganischen Chemie, Titan 41, 455 (1951); based on original work of E. Péchard, Compt. rend. 116, 1513 (1893) and of A. Rosenheim and O. Schütte, Z. anorg. Chem. 26, 253 (1901).

[2] W. S. Clabaugh, R. T. Leslie, and R. Gilchrist, J. Research NBS 55, 261 (1955) RP2628.

Washington, February 1, 1955. 